\title{
Global Warming Offset Effect Regarding Ozone Layer and Chlorophyll a Concentration
}

\author{
Sangyoon Lee
}

\begin{abstract}
As global warming persisted, efforts to predict acceleration of global warming were done bSafaryy many. Recently, $\mathrm{CCN}$ effect has been focused, in the aspect of global warming offset effect by increasing cloud albedo. This research set two independent variables: chlorophyll a and ozone layer. Ozone layer is an important factor for the amounts of chlorophyll a, since too much ultraviolet can denature chlorophyll a. Dependent variable is temperature.

The research set three sea regions where chlorophyll a concentration of recent 15 years has been drastically changed: Nome (USA), Tuktoyaktuk (Canada) and Zaozernaya (Russia). After investigating chlorophyll a concentration and ozone layer through satellite data given by National Aeronautics and Space Administration (NASA) and investigating water temperature by local weather forecasting center, data from 2003 to 2016 were analyzed. Data among chlorophyll a concentration, ozone layer and temperature showed similar tendencies. In particular, in average, when ozone layer thickness was the highest in 2006, chlorophyll a concentration was the highest in 2007, and temperature was the lowest in 2008.

In conclusion, the research could find an overall relationship that is statistically valid among three variables. However, it is clear that there are myriads of confounding variables since this problem is dealing with environmental climate problems. Thus, further research with more data and analysis is necessary.
\end{abstract}

Keywords - CCN, Global warming, chlorophyll a, Ozone layer, polar region

\section{INTRODUCTION}

For recent decades, global warming has accelerated and induced many problems among societies. Moreover, environment pollution and climatic changes caused crisis on Earth and threatened human beings with flooding and drought. Thus, a myriad of trials have been followed by scientists. Actually several policies and solutions were effective and alleviated the level of the global warming. However, many critics state that the global warming is still unpredictable and is proceeding in increasing rate.

Today, some critics state that global warming increases the activation level of chlorophyll a in ocean. In addition, CCN effect leads to twomey effect which makes aerosol increase, and this phenomenon will increase the cloud albedo which will

Sangyoon Lee, Student at Global Vision Christian School, Korea. Email: danny7454@naver.com ultimately counterbalance the degree of global warming by lowering the regional temperature. So this research tried to know the specific degree of how much the CCN effect contributes on the level of the global warming. Also, the research considered a changing ozone layer which would significantly affect the $\mathrm{CCN}$ effect.

This research has collected its data through credible institutions. Its chlorphyll a activation level and ozone layer data were inspected from NASA's satellite picture (http://oceancolor.gsfc.nasa.gov/) and local temperature were collected from local weather forecasting centers. Lastly, the research has used confidence interval and t-test to make the research more precise and accurate.

This research set its basis on the precedent research "Comparison of Hygroscopicity, Volatility and Mixing State of Submicrometer Particles between Cruises over the Arctic Ocean and the Pacific Ocean (2015, Kim KiBaek). The research randomly sampled some regions from East Sea, Sea of Okhotsk, Bering Sea, Chukchi Sea and Beaufort sea where are the samples of the precedent research.

\section{ㅍ. RESEARCH DATA}

A. Nome, U.S.A.

As shown in Fig. 1, Nome, near the Chukchi Sea, is a city located in Alaska. Chlorophyll a concentration is especially high near the coastline of Nome. Also, it is predicted to be highly influenced by change of ozone layer since it is near the polar region.

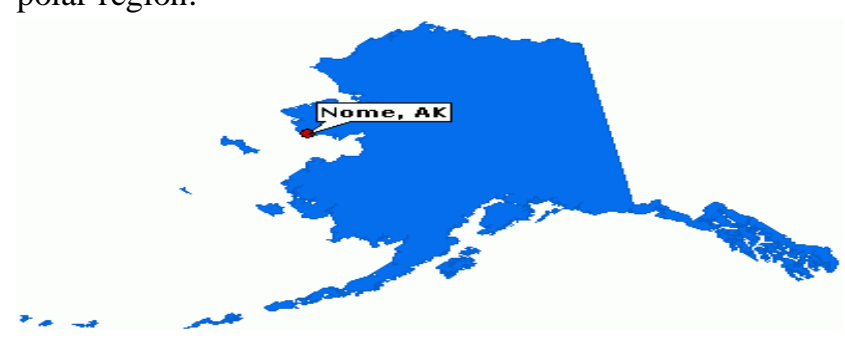

Fig. 1 Nome, Alaska 


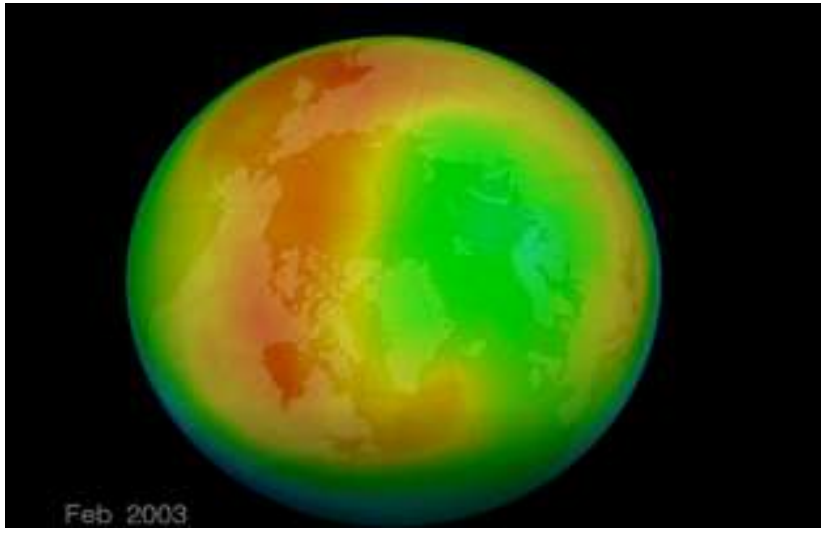

Fig. 2 Ozone layer in 2003, NASA

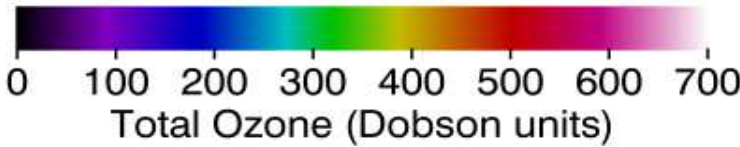

Fig. 3 Ozone layer unit: Dobson

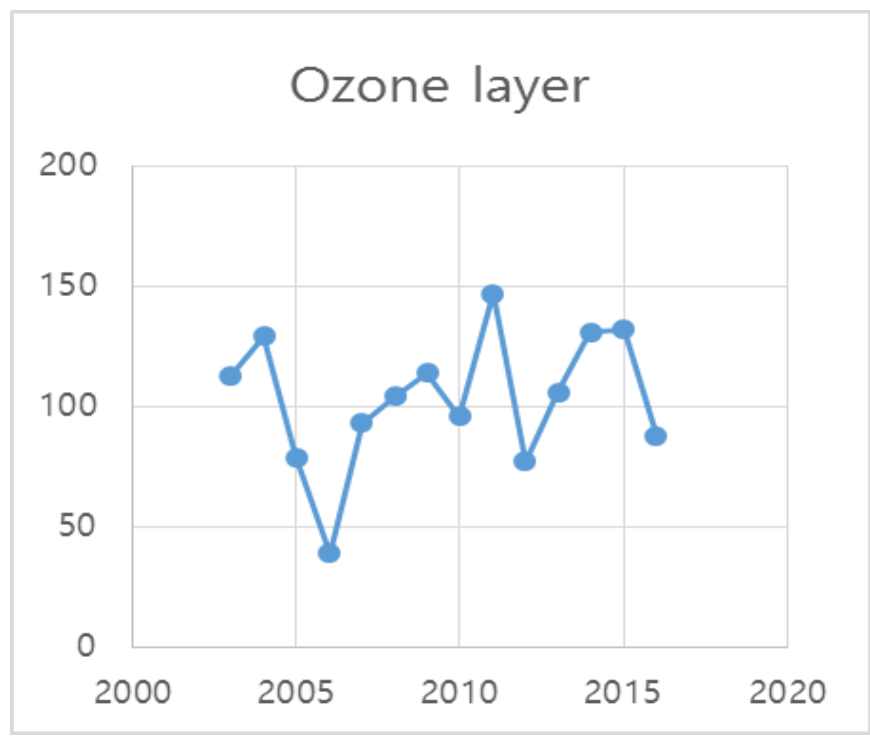

Graph 1 Change in ozone layer above Nome

Graph1 shows that ozone layer unit was rapidly decreasing since 2004 to 2006 and it recovered to its normal phase afterwards.

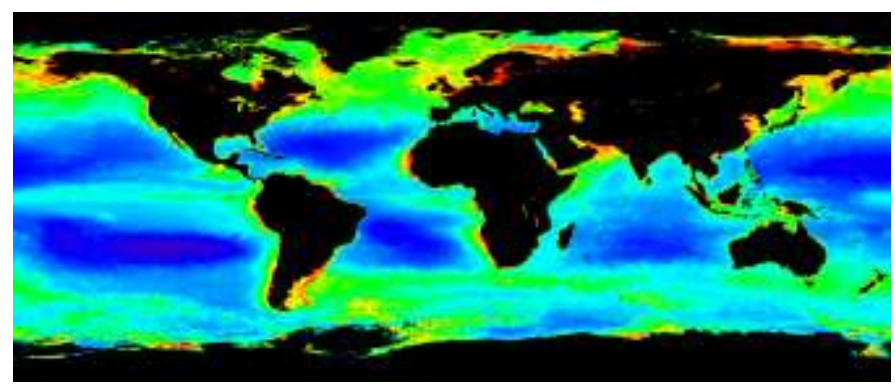

Fig. 4 Chlorophyll a concentration, 2003. Data: NASA

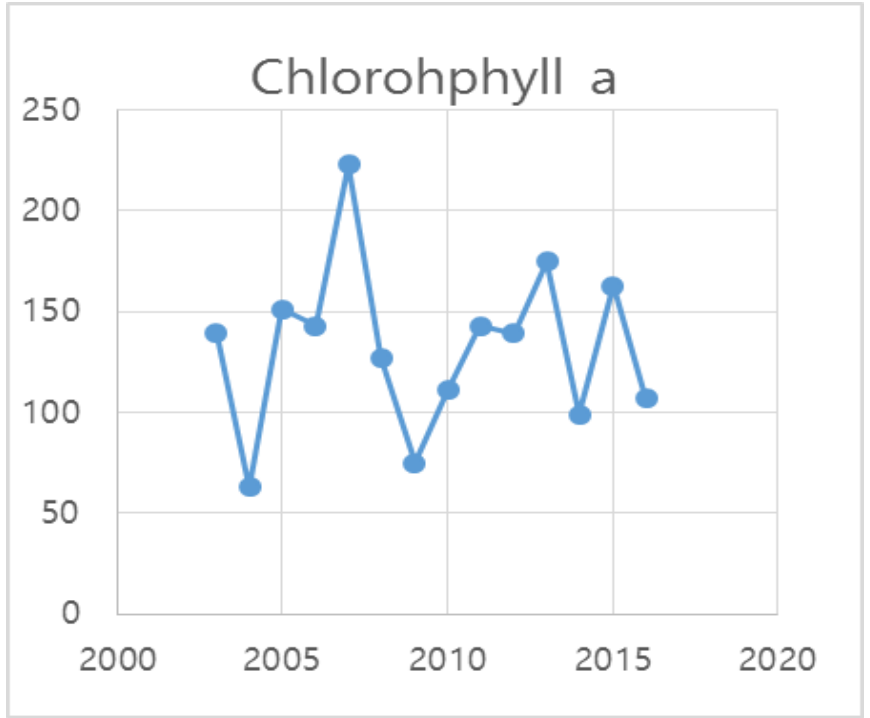

Graph 2. Change in chlorophyll a concentration

Graph 2 shows that chlorophyll a concentration was increasing in an increasing rate from 2004 to 2007.

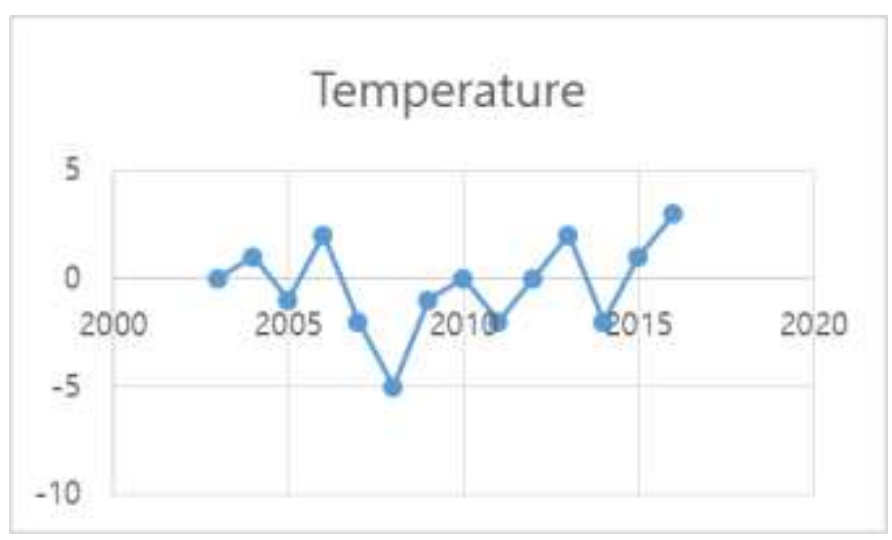

Graph 3. Temperature changing in sea nearby Nome

Graph3 shows that the temperature was decreasing from 2006 to 2008.

\section{B. Tuktoyatuk, Canada}

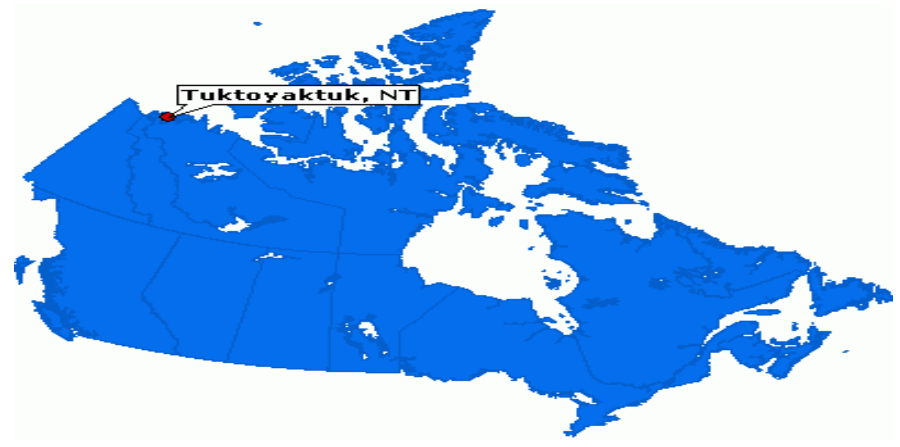

Fig. 5 Tuktoyatuk, Canada 


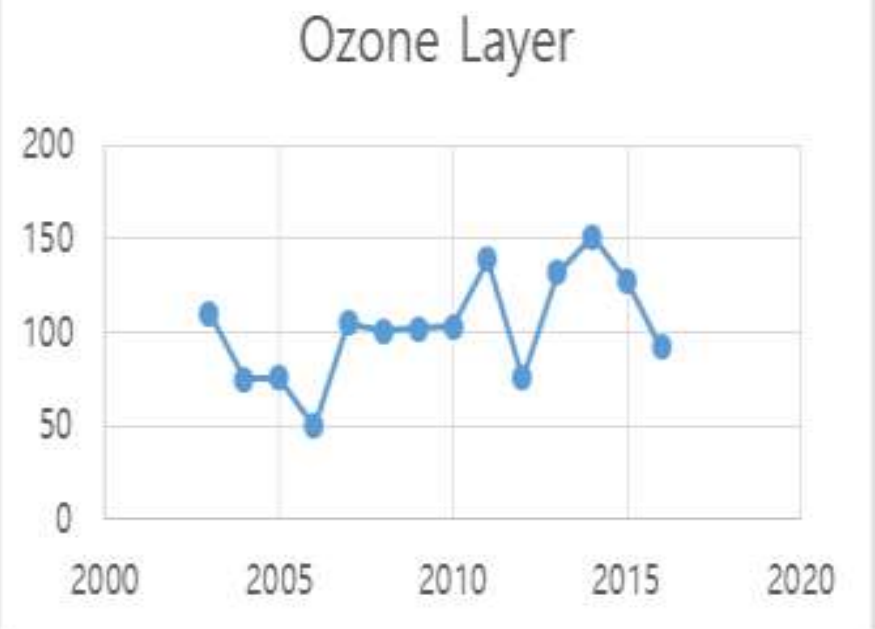

Graph 4. Change in ozone layer above Tuktoyatuk

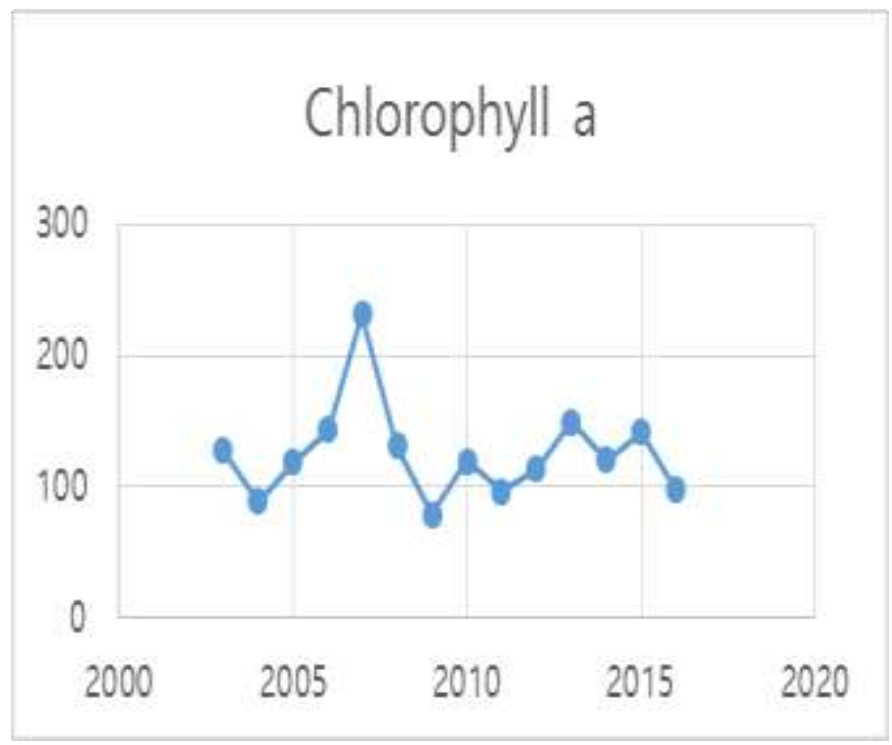

Graph 5. Change in chlorophyll a concentration

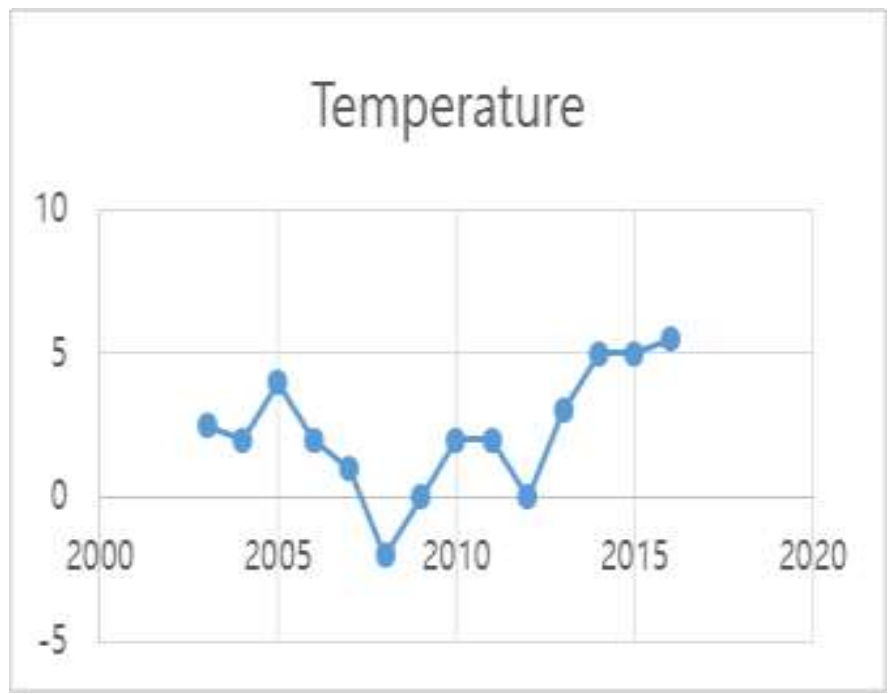

Graph 6. Temperature changing in sea nearby Tuktoyatuk

\section{Zaozernaya, Russia}

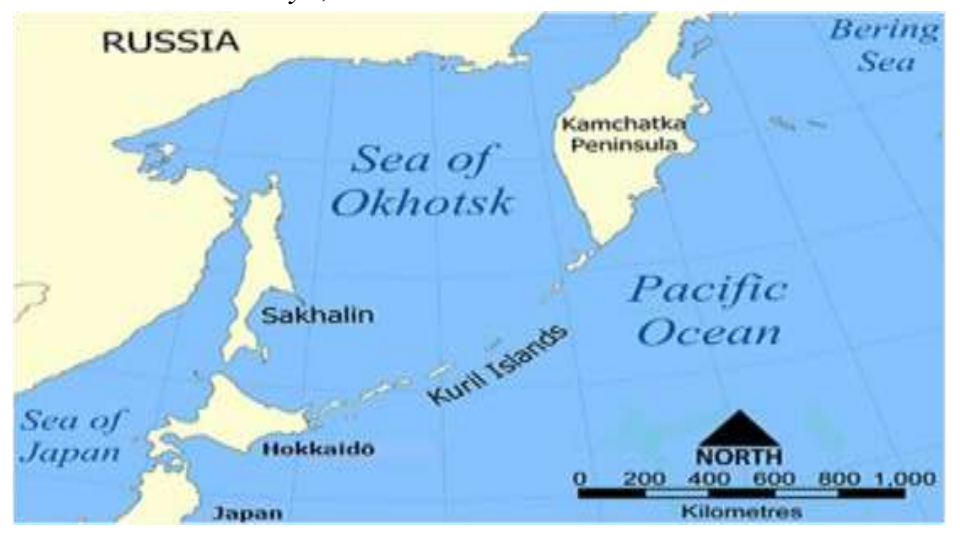

(Diagram6. Zaozernaya, Russia)

\section{Ozone layer}

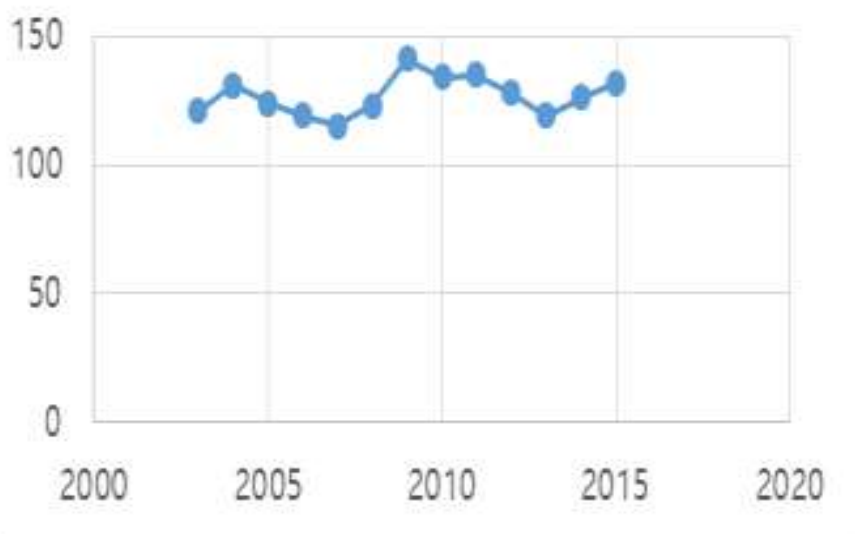

Graph 7. Change in ozone layer above Tuktoyatuk

\section{Chlorophyll a}

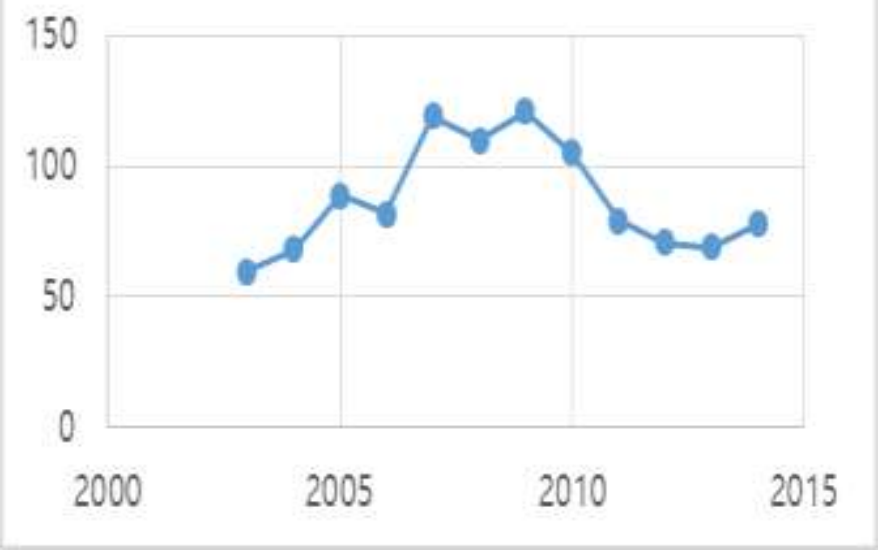

Graph 8. Change in chlorophyll a concentration 


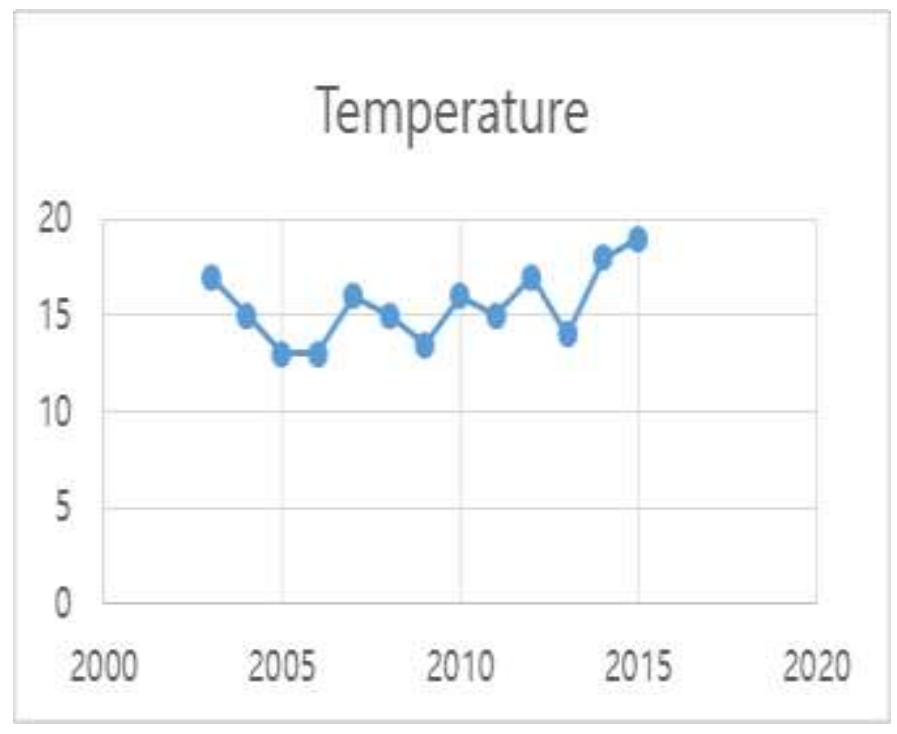

Graph 9. Temperature changing in sea nearby Tuktoyatuk

\section{ANALYSIS}

Comparing and analyzing three different samples of Nome, Tuktoyatuk and Zaozernaya showed a valid correlations between change in ozone layer, chlorophyll a concentration and temperature. First of all, ozone layers above both Nome and Tuktoyatuk region rapidly decreased from 2004 to 2006. Regarding this phenomenon, chlorophyll a concentration in both regions increased from 2005 to 2007. This led to CCN effect and it, again, increased cloud albedo which decreased regional temperature.

Conversely, in the case of Zaozernaya, its ozone layer did not fluctuate a lot; its chlorophyll a concentration did not follow the tendency of ozone layer. Also, other factors like water temperature was fairly constant, thus its regional temperature also did not change a lot.

\section{Conclusion}

Through the research, close relationship between ozone layer, chlorophyll a concentration and temperature was found. Ozone layer's change led to change in chlorophyll a concentration, and finally $\mathrm{CCN}$ effect changed temperature. This research can be used to predict temperature change regarding change in the ozone layer. Particularly, it can be applied to places where a lot of chlorophyll a locates and CCN effect is relatively vulnerable.

Moreover, this research can be also used to predict overall global warming. With the data that global warming offset effect actually exists, predicting global warming progression based on several other factors like the Sun's activity is possible.
Furthermore, it was first predicted that chlorophyll a's life time is more than a year, but considering that its life time is less than 90 dyas (Malavasi, U. C., and M. M. Malavasi, 1999), it is more likely that ozone layer change denaturated DNA or protein that are related to chlorophyll a synthesis.

However, since this research has only a few samples and there are so many cofounding variables existing that may affect the results, it is hard to expect to interpret the conciseness of the global warming offset effect from the data given above. Therefore, it is necessary to analyze the results with more samples and data, and eradicate other influential factors to have more sophisticated model for the offset effect.

\section{REFERENCES}

[1] Merikanto, J., D. V. Spracklen, G. W. Mann, S. J. Pickering, and K. S. Carslaw. "Impact of nucleation on global CCN." Atmospheric Chemistry and Physics 9.21 (2009): 8601-616. Web.

[2] Malavasi, U. C., and M. M. Malavasi. "Leaf characteristics and chlorophyll concentration of Schyzolobium parahybum and Hymenaea stilbocarpa seedlings grown in different light regimes." Tree Physiology 21.10 (2001): 701-03. Web.

[3] Lightle, Kimberly. "Solar Energy, Albedo, and the Polar Regions - Energy and the Polar Environment — Beyond Penguins and Polar Bears." Beyond Penguins and Polar Bears. N.p., n.d. Web. 13 June 2017.

[4] "SJSU ScholarWorks." Site. Terrence R. Nathan, Jan. 2007. Web. 13 June 2017.

[5] "Past Weather in Tuktoyaktuk, Northwest Territories, Canada - Yesterday and Last 2 Weeks." Timeanddate.com. N.p., n.d. Web. 20 June 2017.

[6] ." Weather in Zaozernaya, Sakhalin, Russia | 14 Day Weather Forecast Zaozernaya, Sakhalin. N.p., n.d. Web. 20 June 2017.J. Wang, "Fundamentals of erbium-doped fiber amplifiers arrays (Periodical style-Submitted for publication)," IEEE J. Quantum Electron., submitted for publication.

[7] "Optical constants of AirCiddor 1996: n 0.23-1.690 $\mu \mathrm{m}$." Refractive index of Air - Ciddor. Mikhail Polyanskiy, n.d. Web. 20 June 2017. 